\title{
Synthesis of cyanine dyes: potential fluorescent probes for biological applications
}

\author{
Diego S. Pisoni, ${ }^{\star}$ Marluza P. de Abreu, Cesar L. Petzhold, Fabiano S. Rodembusch, \\ Leandra F. Campo
}

\author{
Instituto de Química, Universidade Federal do Rio Grande do Sul, Av. Bento Gonçalves, 9500, \\ CEP 91501-970, Porto Alegre, RS, Brazil
}

${ }^{*}$ Corresponding author: diego_qui@yahoo.com.br

Keywords: cyanine dyes, fluorescent probes, polymethine

\section{INTRODUCTION}

Cyanine dyes are important organic compounds due to the strong absorption in the visible region, interesting broad wavelength tenability and fluorescence emission in red and infrared regions. ${ }^{1}$ These features allow the use of these dyes as photographic sensitizers, nonlinear optical materials, fluorescent probes for biological and analytical applications. ${ }^{2}$ This work describes the synthesis of cyanine dyes prepared by the condensation of heteroaromatic compounds with a polymethine spacer derived from aniline.

\section{RESULTS AND DISCUSSION}

Symmetrical cyanine 6 was synthesized as shown in Scheme 1. The acid-catalysed condensation of 1,1,3,3-tetramethoxypropane (1) with aniline (2) afforded the polymethine precursor 3. Subsequent alkylation of 2,3,3-trimethylindolenine (4) with excess of 1-iodooctane led to the ammonium salt $\mathbf{5}$ in $75 \%$ yield. Next, the condensation reaction of polymethine 3 (1.0 equiv.) with $3 \mathrm{H}$-indolium salt 5 (2.0 equiv.), under reflux in $\mathrm{EtOH}$ in the presence of $\mathrm{AcONa}$, afforded the symmetrical cyanine dye 6 in $54 \%$ yield.

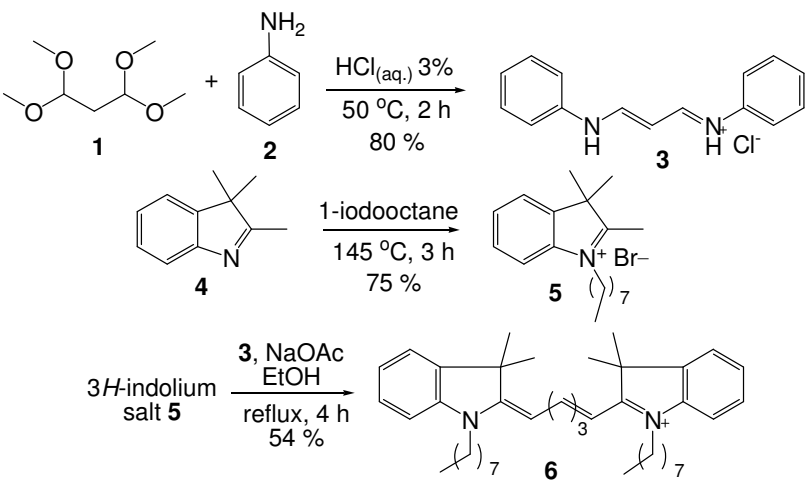

Scheme 1. Synthesis of cyanine 6 .

Cyanine 8 was obtained in $46 \%$ yield by condensation of polymethine 3 with $3 \mathrm{H}$-indoliumacid 7, prepared by alkylation of 4 using 6bromohexanoic acid in o-dichlorobenzene (Scheme 2). Unsymmetrical dye $\mathbf{1 0}$ was synthesized $14^{\text {th }}$ Brazilian Meeting on Organic Synthesis - 14 $4^{\text {th }}$ BMOS - September 01-05, 2011-Brasilia, Brazil according to Scheme 3 . Condensation of 3 (1.0 equiv.) with 5 (1.0 equiv.), in the presence of $A_{2} \mathrm{O}$ as solvent, afforded the acetanilinobutadienyl salt $\mathbf{9}$ in $70 \%$ yield. Subsequent reaction of activated indolium 9 with 7, under reflux in $\mathrm{EtOH}$ in the presence of $\mathrm{AcONa}$, led to the dye $\mathbf{1 0}$ in $55 \%$ yield.

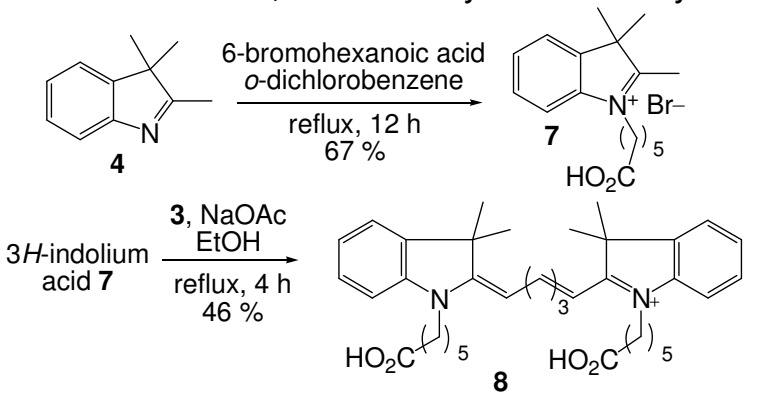

Scheme 2. Synthesis of cyanine 8.

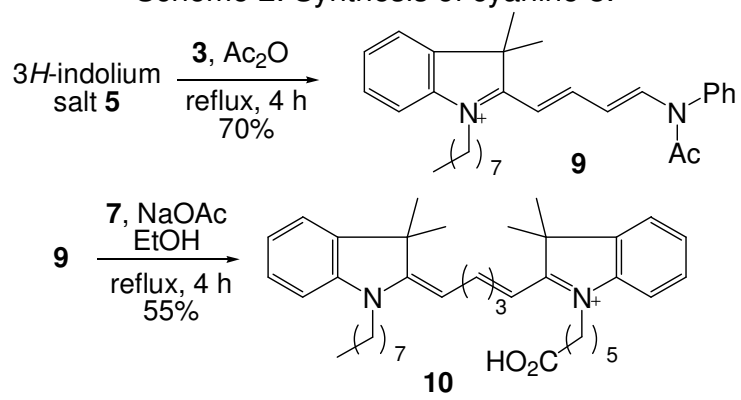

Scheme 3. Synthesis of cyanine 10.

The synthesized dyes exhibit in solution absorption and fluorescence emission in the red region $(660-670 \mathrm{~nm})$.

\section{CONCLUSION}

The dyes 6, 8 and $\mathbf{1 0}$ were synthesized by the condensation of heterocyclic ammonium salts with polymethine precursor 3 . These compounds exhibit interesting photophysical properties for application in fluorescence microscopy and fluorescence imaging.

\section{ACKNOWLEDGEMENTS}

INDI-Saúde and CNPq for finantial support.

\section{REFERENCES}

${ }^{1}$ Mojych, M. et at. Top. Heterocycl. Chem. 2008, 14, 1.

${ }^{2}$ Chipon, B. et al. Tetrahedron Lett. 2006, 47, 8279. 